Article

\title{
Considering the Practical Rationality of Experimental Operation in Developing Countries: Reality and Challenges under a Rigid Community Forestry System in Cambodia
}

Takayuki Kurashima ${ }^{1, *}$, Toshiya Matsuura ${ }^{2}$, Asako Miyamoto ${ }^{2}$, Makoto Sano ${ }^{2}$ and Sophal Chann ${ }^{3}$

1 Division of Southeast Asian Studies, Graduate School of Asian and African Studies, Kyoto University, 46 Shimoadachi-cho, Yoshida, Sakyo-ku, Kyoto 606-8501, Japan

2 Department of Forest Management, Forestry and Forest Products Research Institute, 1, Matsunosato, Tsukuba, Ibaragi 305-8687, Japan; E-Mails: matsuu50@affrc.go.jp (T.M.); asakom@affrc.go.jp (A.M.); masakoto@affrc.go.jp (M.S.)

3 Institute of Forest and Wildlife Research and Development, Forestry Administration, Street 1019, Phum Rongchak, Sankat Phnom Penh Thmei, Khan Sen Sok, Phnom Penh 12101, Cambodia;

E-Mail: sophal.chann@yahoo.com

* Author to whom correspondence should be addressed; E-Mail: kurashima@asafas.kyoto-u.ac.jp; Tel.: +81-29-829-8313; Fax: +81-29-873-3720.

Academic Editors: Eric J. Jokela and Brian J. Palik

Received: 20 April 2015 / Accepted: 29 August 2015 / Published: 7 September 2015

\begin{abstract}
Influential stakeholders have highlighted many constraints inherent in conventional scientific forest management plans for community forestry (CF) and presented simpler alternatives. Nevertheless, some developing countries continue to use rigid, complex and high-cost plans and regulations. This article considers two issues: (1) why heavily-regulated or rigid CF systems were originally introduced and why they continue to be used in developing countries despite critiques and counterproposals; and (2) under what circumstances will such $\mathrm{CF}$ systems face an impasse, and what can be done to resolve the situation. Using Cambodia as a case study, we examine the development of a rigid CF system, review negative factors influencing the upland forested area, clarify the unfavorable situations arising from these factors and discuss likely problems associated with the CF management system. International organizations played a key role in the introduction and maintenance of rigid, complex and high-cost CF systems in Cambodia. Conflicts and crises arise when the administration prosecutes local farmers for illegal cultivation or deprives communities of CF
\end{abstract}


management rights because of the expansion of commercial crop cultivation and the lack of adequate community management in response to unprecedented changes. A likely practical solution to the probable impasse is the development and funding of a functional network of CF management committees, rather than the adoption of an entirely new, alternative system.

Keywords: community forestry; scientific forest management; upland use; commercial crop expansion; organizational network; Cambodia

\section{Introduction}

In 2004, the Food and Agriculture Organization of the United Nations (FAO) issued a working paper regarding participatory forestry in developing countries [1]. It pointed out many constraints that are imposed when scientific conventional forest management plans are utilized for participatory forestry, such as community forestry (CF; also refer to the abbreviation list on the final page), and then presented guiding principles to be used when constructing a simpler forest management plan, together with selected examples [1]. Although the FAO has been the most influential organization in the forestry sectors of developing countries, other more complex CF plans and regulations have been used in many developing countries even after the publication of the working paper [2-8]. Consequently, some stakeholder organizations, including the FAO, and their CF experts have recently criticized the rigid, complex and high-cost CF systems [3-8]. Moreover, alternative management approaches have been developed, e.g., "minimum standards" and the "simple management plan", as proposed by the FAO a decade ago [5,7-9].

The context in which FAO officials recommended a simpler plan for participatory forestry was intended partly to achieve long-term sustainability rather than near-term outcomes. The officials believed that internal learning, debates and negotiation in each community were crucial for establishing a strong collective forest management institution and that the plan preparation process should be used as a catalyst for such capacity building [1]. For the capacity building of communities, they considered that simple and flexible plans were better suited than the more rigid and complex alternatives. In contrast, more recent critiques are based on the opposite assumptions. For example, Fisher was concerned that the CF management systems, in which bureaucratic organizations hold discretionary powers through heavily detailed regulations, disempower local people from forest resource management and consequently lead to an increase in the absolute poverty of people [8].

An extensive meta-study at the pantropical scale [10], as well as other studies [11], has reported that CF management has had a deterrent effect on deforestation in general, despite a methodological critique of the meta-study [12]. However, because the meta-study gave little consideration to how the CF sites have been and will be managed, it is difficult to identify which types of CF management (e.g., simple or complex) most effectively discourage undesired deforestation. In addition, if some management systems, e.g., those in which bureaucratic organizations hold discretionary powers through heavily-detailed regulations, do actually disempower local people and lead to an increase in their poverty as a consequence of strengthening central bureaucratic powers, as Fisher fears [8], the CF systems would significantly contradict the basic values that modern CF management should support (see [13]), 
particularly the empowerment of forest users and poverty alleviation, even if such systems help to improve forest conditions.

This article considers two issues that evolve from these concerns related to particular CF systems. The first is why and how the rigid or heavily-regulated CF systems were introduced and have been operated in some developing countries even after having received critiques and counterproposals from influential stakeholders. The other is under what actual circumstances such CF systems will face an impasse and then what can be done to address the situation. To answer these questions, the process of developing such CF systems, some current negative factors influencing the surrounding forested area, and two unfavorable situations arising from the negative factors were investigated using a region of Cambodia as a case study. Furthermore, we discuss the likely problems associated with the CF management systems and practical solutions for these problems.

With respect to the introduction and enforcement of rigid CF systems, some studies have suggested that the influence of bureaucratic thinking or behavior has played a key role $[3,4,6]$. However, few studies have noted the implicit factors that make the application of bureaucracy to a CF system possible in developing countries, as well as the specific process itself, although an exceptional policy brief has hinted at the structural aspects embedded within international assistance aid, such as the "aid dilemma" [14]. This article considers these factors, including the support framework for the introduction and enforcement of a rigid CF system, by focusing on the process. To resolve the impasse in establishing CF systems, this article considers practical measures for developing CF management under the current system, i.e., practices that differ from those (such as "minimum standard" and "simple management plan") proposed by some experts.

After a brief examination of the characteristics of the research site and methodology, we first survey the current Cambodian CF management system. Next, the prehistory and de facto processes for the enforcement of such a CF system are clarified, with a focus on a district within a province. Then, we examine the unstable land use situation that many CF sites and their surroundings in Cambodian upland areas currently exist under, as well as the concern for future CF development, using the same district as a case study. Finally, two questions regarding CF development are raised and answered. In the discussion, we consider the CF system in other countries where that system is at a more developmental stage than in Cambodia, as well as information from the Cambodian National Forest Program, to evaluate the evolution and future of the Cambodian CF system.

\section{Research Site and Methods}

This study focused on the CF system in Cambodia. For the field survey, Sandan (SD) District in Kampong Thom (KT) Province was selected (Figure 1), because the current CF system has been described as rigid, complex and expensive [2,15-17]; the district, particularly its upland area, includes CF sites that are larger and greater in number than in other districts in Cambodia, and the upland area of the district currently faces problems similar to those found in other upland areas across the country, i.e., rapid increases in population and huge expansions in commercial crop cultivation. 


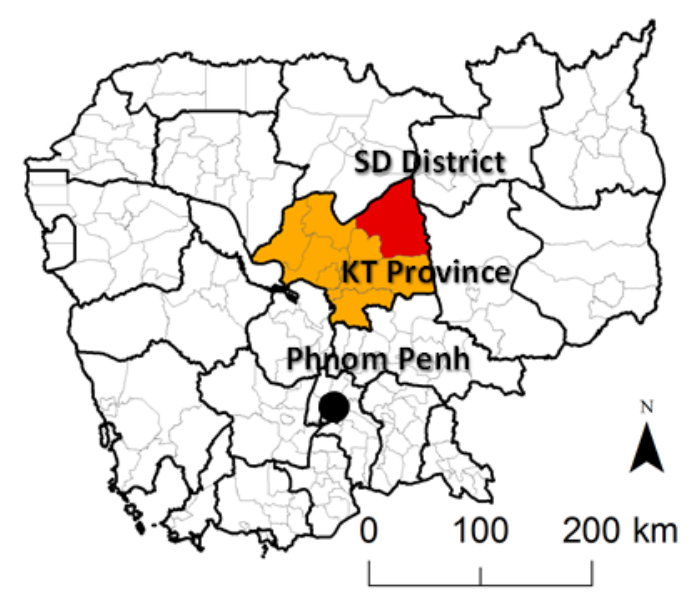

Figure 1. Location of Kampong Thom (KT) Province and Sandan (SD) District in Cambodia.

For this study, we conducted four types of research: document collection and review; satellite image interpretation; field observations; and interviews with stakeholders. Based on the results, we analyzed various factors. In particular, the likely problems associated with the CF management system, and practical solutions to these problems were considered by interlinking the multiple confirmed factors and our analyses.

The document collection and review targeted not only forest management systems, but also rural land use in Cambodia in general. The satellite imagery was used for interpreting changes in land cover using Landsat imagery taken in January 2009 and in January 2014, focusing on the Normalized Difference Vegetation Index (NDVI). Field observations and interviews were conducted mainly during 2013-2014. These involved a survey of $18 \mathrm{CF}$ sites and their surroundings within the district by car, motorbike and on foot, as well as interviews conducted with stakeholders, such as village leaders, leaders and members of CF management committees, the staff of local and international non-governmental organizations (NGOs), and local forestry and other administration officials. In the interviews, particularly those with villagers, enquiries were made into the development histories of land use and livelihood activities, as well as those of natural resource management strategies, including CF.

\section{Overview of the Current Cambodian Community Forestry System}

\subsection{Regulatory Components and Content}

The current Cambodian CF system consists mainly of three pieces of legislation: the Forestry Law of 2002, the Sub-decree on CF management of 2003 and the Guideline on CF of 2006 (2006 CF Guideline) [18]. Although the first Forestry Law of 2002, unlike the other two pieces of legislation, was not specifically for $\mathrm{CF}$, it directly or indirectly controlled the structure and content of the other two pieces of legislation by establishing their requisite constitutions and guaranteeing that the initiatives would be managed by the Ministry of Agriculture, Forestry and Fisheries (specifically, the Forestry Administration) [19].

The Forestry Law of 2002 outlines the general rules and regulations related to the administration and management of "the Permanent Forest Estate" within Cambodia and defines the basic structures, functions and responsibilities of the Forestry Administration [19]. It sets out the rules and regulations regarding logging concession management, forest crimes, wildlife management, traditional user rights 
and CF [20]. For traditional user rights, the law targets local communities living within or near the Permanent Forest Estate, assuring their subsistence consumption of forest products and by-products, without a requirement to obtain permission [19]. With respect to CF that enables utilization for commercial purposes in a particular demarcated site along with subsistence, the law targets the same communities, endorsing their rights to establish and manage sites under certain conditions [19]. The conditions mainly comprise the conclusion of a CF agreement with the local Forestry Administration; the preparation of a CF management plan that conforms to official guidelines (originally published in mid-2006); the approval of the CF management plan by the central Forestry Administration; and the abidance of both the CF agreement and CF management plan. In addition, the Forestry Law of 2002 requires the implementation of an Environmental and Social Impact Assessment for any activity that may have an adverse impact on society and the environment [19].

The sub-decree on CF management of 2003, which was derived from the Forestry Law of 2002, defines the fundamental procedures and rules for the establishment, management and use of CF sites and establishes the role of the CF management committee, CF agreement and CF management plan [20,21]. For example, it states that each CF shall be led by a CF management committee, with the CF management committee's members selected from CF members in an election attended by at least two-thirds of CF members [21]. The CF members, as cited in the sub-decree, are Cambodian citizens living within one or more villages, who share a common socio-economic interest and use the natural resources in the area. Each CF member can only become a member of one CF site [21]. Furthermore, the sub-decree specifies the authority of the Forestry Administration, as well as the duties and roles of CF members. Under the sub-decree, CF members have the following duties and roles: participating in the development and implementation of the CF agreement and CF management plan in compliance with official guidelines; participating in conserving, protecting and planting the forest; and following the instructions of the Forestry Administration [21]. In contrast, the Forestry Administration has the following duties and roles: demarcating the exact forest area for CF; making decisions that recognize, reject or terminate CF sites; reviewing, revising and approving $\mathrm{CF}$ agreement and $\mathrm{CF}$ management plan; developing official guidelines that are relevant to $\mathrm{CF}$ management; monitoring and evaluating $\mathrm{CF}$ processes; providing technical support; and enforcing the implementation of legislation, including the CF agreement and CF management plan [21].

In addition to other factors required for CF site establishment, such as the areal criteria and the assent of at least $60 \%$ of all households in each village, the 2006 CF Guideline provides more detailed content related to the establishment of the $\mathrm{CF}$ agreement and $\mathrm{CF}$ management plan. In particular, the descriptions related to the CF management plan are noteworthy in the context of this article, because they are regarded as the most time-consuming and costly part, as specifically clarified in a later section. The CF management plan characteristics are based on the scientific forestry method, which consists of a disciplined block division, forest inventory and harvesting plan [22]. For example, if CF sites are 1000-1500 ha; they need to consist of 40-60 and 60-90 sample plots, each as large as $50 \times 100 \mathrm{~m}$, for deciduous and evergreen or semi-evergreen forest, respectively [22]. Timber is identified and counted by distinguishing three and five classes in terms of girth and species, together with the identification and counting of seedlings, coppices and non-timber forest products in smaller sample plots [22]. From the results obtained, precise harvesting plans need to be established that target the valid period of each CF management plan. 
Table 1 shows the 12 steps in the current Cambodian CF system, which incorporate most of the above procedures and operations. We briefly explain some of the important steps here. Step 0 is the identification and approval by the administration of the area to be used for CF. Step 3 is the formation of the CF management committee (CFMC). Step 7 is the conclusion of a CF agreement (CFA) between the $\mathrm{CF}$ management committee (CFMC) and the local Forestry Administration. Step 8 is the preparation of the CF management plan (CFMP), which is drafted by the CF management committee (CFMC) or local NGO in most cases, and the approval of the CF management plan (CFMP) by the central Forestry Administration. Strep 9 is the enterprise and livelihood development for the community. Step 10 is the implementation of the CF management plan (CFMP), and finally, Step 11 is monitoring and evaluation undertaken by the Forestry Administration to determine whether the CF management committee (CFMC) complies with the CF agreement (CFA) and the CF management plan (CFMP) [18]. Additionally, multiple sub-steps exist within the CF management planning and inventory process (i.e., Step 8).

Table 1. The steps involved in formalizing a community forestry (CF) site in Cambodia.

\begin{tabular}{l|l}
\hline Step 0: CF area identification and approval & Step 6: Preparation of CF regulations \\
\hline Step 1: CF formulation & Step 7: Preparation and approval of CFA \\
\hline Step 2: Information gathering & Step 8: CF management planning and inventory \\
\hline Step 3: Establishment of CFMC structure & Step 9: Enterprise/livelihood development \\
\hline Step 4: Development of CFMC internal rules & Step 10: CFMP implementation \\
\hline Step 5: Demarcation of boundaries and mapping & Step11: Monitoring and evaluation \\
\hline
\end{tabular}

Sources: Blomley et al. [18]; Kingdom of Cambodia [16]; Poffenberger and Long [23].

\subsection{Introductory Process and Formative Background}

The current Cambodian CF system is considered "rigid and complex" [15-17]. Why or how has this "rigid and complex" CF system, particularly represented by the sub-decree of 2003 and the $2006 \mathrm{CF}$ Guideline, arisen? Primarily, we note the existence of two interacting factors during the introductory and subsequent periods. The first stems from the bureaucratic and systematic behavior of the Cambodian government and international assistance aid organizations, and the second arises from the dual character of the current Cambodian CF system and the previous policy environment, which affected land uses within the Permanent Forest Estate. The first interaction occurred when the introduction of the CF system proceeded within a series of reforms across the entire Cambodian forestry sector. We consider that this introductory process resulted in background conditions that structurally discouraged some stakeholders, including international aid organizations, from insisting on a "simple" or "minimum" structure for the Cambodian CF system. In the second interaction, an important point was that the establishment of a CF system actually stabilized the site for communal resource management to some extent, even if the CF system required communities to undertake much additional work. Here, we further explain each interaction.

Although Cambodia once had a stable commercial logging system until the 1970s [24], the continual political turmoil ensured that vast areas of forest remained unharvested for long periods. A logging concession system throughout the country occurred after the provisional rule of the United Nations at the beginning of the 1990s. However, the system, which was based on the investment agreements and forest timber licenses not referring to any law [25], soon came to be regarded by international societies as unsustainable $[25,26]$. Thus, the Cambodian logging concession system was targeted for reform by 
the Cambodian government and international stakeholders, particularly the Asian Development Bank, the World Bank and the International Monetary Fund, in the late 1990s (see [25-30]). In addition to logging concessions, some other forestry sub-categories, including CF management, had been examined together since then (see $[25,31,32]$ ). The design process for CF management that was integrated into the entire forestry sector reform program led to the development of the particular CF system that was established.

The Cambodian forestry sector reform, which consisted of multiple sub-categories, was a national-scale program in which the sovereign state had ultimate responsibility, but which was sponsored by the Asian Development Bank, the World Bank and the International Monetary Fund. The Forestry Administration, a competent bureaucratic organization under the control of the Cambodian government, got involved in a series of operational processes, with a timeline for the program set by agreement between the administration and international stakeholders. In general, the bureaucratic organization handling natural resource management takes charge of duties and roles according to the specific regulations and enforces those regulations. Therefore, it was highly likely that the Cambodian Forestry Administration, a bureaucratic organization, stuck to the regulatory drafts in forms that are not "simple" and "minimum" (see [33]), even if the target for the duties and roles was CF.

By contrast, an overseas expert, i.e., a legal advisor from an NGO working on the Cambodian CF program, pointed out that a specific provision within a draft of the $2006 \mathrm{CF}$ Guideline (namely, the provision regarding the Environmental and Social Assessment required for each CF management plan) was problematic because of its "seemingly unnecessary bureaucratic requirements" [34]. However, the claim was not intended to hide the radical principles of the entire Cambodian CF system so that the alternative CF system had "simple" and "minimum" regulations. This expert's response, neither claiming the need for conversion in principle nor blocking the entire reform process, was likely reasonable, given the approach and timeline of the series of reform programs operated by the Cambodian government and international societies (see [32]).

The dual character of the current Cambodian CF system in the second interaction specifically indicated that the system called on communities to recognize many procedures and to undertake work, while also helping them to secure their CF sites to some extent. Some international stakeholders initially attached much more importance to the latter than to the former aspect of the Cambodian CF system under the emergent policy environment of that time. One such body was the Center for People and Forests (RECOFTC), a key assistance body for the Cambodian CF since the mid-2000s. In addition, some experts considered that the guidelines, unlike a law, could be altered relatively easily if problems arose at a later stage [34]. This institutional context and the recognition of stakeholders likely had an effect on the evolution of the 2006 CF Guideline.

For example, the RECOFTC often stated that the characteristics of the current Cambodian CF system were "rigid and complex" $[15,17,35]$ and referred to the need for revision $[17,36]$. Meanwhile, the organization has continued to support the site designation process under the same CF system [37,38]. Why has the body behaved like this, despite its recognition of the problem with the current Cambodian CF system? A possible explanation is that the organization prioritizes CF site establishment in the early stages, as stated above. There may be an underlying cause for this, although it may also be influenced by the responses of some other international stakeholders. The underlying cause is that some policy circumstances relevant to the Permanent Forest Reserve, particularly the activation of the controversial 
Economic Land Concession (ELC) policy for large-scale land developers (see [30,39-41]), heightened the need to initially ensure the CF sites (see [36,37]), as well as the scheduled international assistance aid programs for Cambodian CF (see [42]).

Many of the envisioned domains for the ELCs, whose selection process was often criticized for lacking transparency [39-41,43-46], overlapped the areas where logging concessions had been previously granted [47], even in locations where zoning was required to alter the land from state public property to state private property. Such areas were expected to be used as CF sites [34,48]. The Forestry Law of 2002 guaranteed customary user rights to community members living within or near the Permanent Forest Reserve [19], which was a sub-category of state public property, as already explained. Thus, there were no legal restrictions on daily forest use for subsistence purposes by community members, irrespective of the CF site designation, as long as the area was zoned as Permanent Forest Reserve. However, the conversion to an ELC site, during which the remaining natural forests were clear-cut and a monoculture was planted, meant that these rights of usage for the community virtually disappeared, as did the rights of CF site establishment. Given the competitive relationship with these ELC sites, it was important to rapidly legitimize CF sites and then to secure CF tenures.

\subsection{Estimating the Cost and Time for the Establishment of Each Site, Planning the Whole Program} and Designating the Actual Site

A cost and time estimation based on information from the Forestry Administration indicated that 15,000-18,000 USD and 100-135 days would be required for the CF management planning and inventory per site, which corresponded to one of twelve CF establishment steps [18]. The GDP (gross domestic product) per capita of Cambodia was 782 USD in 2010 (current price) [49]. In addition, the same report indicates that 47,000-54,900 USD and 305-390 days per site would be required to implement 8-10, save Step 9 (enterprise and livelihood development), of the 12 steps, which are shown in Table 1, although this varied from site to site [18].

The National Forest Program (NFP), which has comprehensively prescribed Cambodian forest policy for the period of 2010-2029 after negotiations with international stakeholders, considers CF to be one of six important implementation programs [16]. With regards to CF, the NFP recognizes a variety of issues from programmatic risks to development support methods, the introductory background, regulatory framework and expected results, although only a brief description of each of these subjects is given. The NFP claims that 18 million USD will be required in the first decade to achieve the goal of finally creating two million ha of CF sites (the total land area of Cambodia is 17.6 million ha), with six million USD over the first five years as the estimated contribution from international aid donors. This suggests that the Cambodian government currently intends to actively implement CF policy with the support of international societies, but official measures started only relatively recently, compared to other developing countries.

The latest CF statistics (issued in June 2013), six and half years after the publication of the 2006 CF Guideline, revealed that the status of CF development in the whole of Cambodia was as follows: 457 sites ( 0.4 million ha) had been examined for CF management; 345 (almost 0.31 million ha) of the 457 were approved by the administration; and 253 (almost 0.21 million ha) of the 345 finalized a CF agreement [50]. In addition, only one of the 253 sites received approval from the central Forestry 
Administration for a submitted CF management plan [17]. On the conclusion of a CF agreement, the CF management committee is granted the exclusive management rights over an extendable 15-year period for the subsistence utilization of community members and neighbors, although the rights for non-timber forest products can be sold at any time. In contrast, the CF management committee can start commercial utilization with the permission of the CF management plan, especially for timber, any time within the valid period of the CF agreement, with the exception of the first five years [22].

\section{Prehistory and Implementation Process of the Cambodian Community Forestry System: A Case Study of Sandan District, Kampong Thom Province}

Kampong Thom (KT) Province is located in central Cambodia, which is where CF policy has been implemented most actively (Figure 1). Sandan (SD) District at the eastern extremity of the province has a greater number of and the largest CF sites in the province. The district experienced political turmoil throughout the 1970s and 1980s, including battles between armed forces of the Khmer Rouge and successive governments, in addition to periodically being controlled by such regimes. Thus, the increase in population and the development of land exploitation was limited until the early 1990s. The characteristics of a small population, with a vast thick forest, did not generate the necessity and incentives for communities to create specific styles of endogenous forest management systems, such as CF. Our research has indicated that there was no attempt at CF management in the area until around 2000.

A tense situation that developed between local villagers and a logging concession company acted as the trigger for the introduction of CF management. Tensions arose because a subcontractor harvested trees used by the villagers for resin collection without prior consent. With the aid of local and international non-governmental organizations (NGOs), some villagers later travelled to the national capital to protest against the injustice of logging concession practices. A process of forestry management reform was initiated among the various stakeholders, with the protests connected by international and local NGOs to the evolution of logging concession reform and the introduction of CF. The logging company and the Forestry Administration agreed to establish some CF sites within the concession area. An international NGO based in Great Britain and the United States provided the funding, and some local NGOs helped communities to establish CF sites, although the process had to be later repeated due to the newly published 2006 CF Guideline. Of the CF sites that remain, approximately half were established in the early 2000 s via the evolutionary process described above, while the rest were developed after the 2006 CF Guideline was established.

Table 2 shows the details of the 31 CF sites situated in Sandan District in September 2014, including two important factors related to the questions raised in this study. After almost eight years had passed since the publication of the 2006 CF Guideline, half of the sites had reached the phase of CF management planning and inventory (i.e., Step 8). Twelve sites in the remaining half were still at Step 0; i.e., identification of the CF area and approval by the administration. Many CF sites, even if they were in Step 8, required a certain length of time until they received a CF management plan from the Forestry Administration, because Step 8 was the most expensive and time consuming of the various steps. Most of the sites that had reached Step 8 were still in Sub-step 5, which meant that each site was in the middle of implementing a complex forest inventory and drafting a harvest plan. This involved an elaborate field 
survey and the estimation of forest resources. Therefore, each site needed to go through three more sub-steps, including an in-depth check of the CF management plan by the Forestry Administration.

Table 2. Details of the community forestry (CF) sites in Sandan District (September 2014).

\begin{tabular}{|c|c|c|c|c|c|c|c|}
\hline \multirow[b]{2}{*}{ No. } & \multirow{2}{*}{$\begin{array}{c}\text { CF } \\
\text { Name } \\
\text { (pseudo) }\end{array}$} & \multicolumn{3}{|c|}{ Month/Year } & \multirow{2}{*}{$\begin{array}{c}\text { Implementing } \\
\text { Organization }\end{array}$} & \multirow{2}{*}{$\begin{array}{l}\text { Fund } \\
\text { Source }\end{array}$} & \multirow{2}{*}{$\begin{array}{r}\text { CFMP } \\
\text { Steps } \\
(1 \rightarrow 8) \\
\end{array}$} \\
\hline & & Establishment & Approval & Agreement & & & \\
\hline 1 & DPCS & 2002 & $11 / 2008$ & $11 / 2009$ & MB & EU & 8 \\
\hline 2 & PNT & 2002 & $11 / 2008$ & $11 / 2009$ & MB & $\mathrm{EU}$ & 8 \\
\hline 3 & PKOK & 2004 & $11 / 2008$ & $11 / 2009$ & MB & $\mathrm{EU}$ & 8 \\
\hline 4 & PHC & 2001 & 08/2010 & 08/2011 & MB & $\mathrm{EU}$ & 5 \\
\hline 5 & LS & 2001 & $08 / 2010$ & 08/2011 & MB & EU-USAID & 5 \\
\hline 6 & $\mathrm{OBL}$ & 2001 & 08/2010 & 08/2011 & $\mathrm{MB}$ & EU-USAID & 5 \\
\hline 7 & PKOT & 2002 & $11 / 2008$ & $03 / 2010$ & AFD & EU-OGB & 5 \\
\hline 8 & PKT & 2003 & $11 / 2008$ & $03 / 2010$ & AFD & EU-OGB & 5 \\
\hline 9 & PPR & 2008 & $08 / 2010$ & $06 / 2012$ & $\mathrm{MB}$ & EU-USAID & 5 \\
\hline 10 & PSP & 2009 & $08 / 2010$ & $06 / 2012$ & MB & EU & 5 \\
\hline 11 & $\mathrm{PT}$ & 2002 & $11 / 2008$ & $11 / 2009$ & MB & EU-USAID & 3 \\
\hline 12 & OKN & 2003 & 08/2010 & $06 / 2012$ & MB & EU & 3 \\
\hline 13 & ODS & 2001 & $08 / 2010$ & 08/2011 & MB & EU-USAID & 2 \\
\hline 14 & POT & 2001 & $11 / 2008$ & $11 / 2009$ & MB & EU & 1 \\
\hline 15 & PKS & 2002 & $11 / 2008$ & $11 / 2009$ & MB & EU & 1 \\
\hline 16 & $\mathrm{KP}$ & 2001 & $08 / 2010$ & $06 / 2012$ & & USAID & \\
\hline 17 & POL & 2001 & 08/2010 & $06 / 2012$ & & & \\
\hline 18 & POP & 2002 & $11 / 2008$ & $11 / 2009$ & & & \\
\hline 19 & POR & 2002 & $11 / 2008$ & $11 / 2009$ & & & \\
\hline 20 & PKDT & 2001 & & & & USAID & \\
\hline 21 & $\mathrm{KC}$ & 2008 & & & & & \\
\hline 22 & PK & 2008 & & & & & \\
\hline 23 & KK & 2008 & & & & USAID & \\
\hline 24 & Svy & 2008 & & & & USAID & \\
\hline 25 & AP & 2008 & & & & USAID & \\
\hline 26 & KR & 2008 & & & & USAID & \\
\hline 27 & $\mathrm{PC}$ & 2008 & & & & & \\
\hline 28 & $\mathrm{Krg}$ & 2009 & & & & USAID & \\
\hline 29 & $\mathrm{BR}$ & 2009 & & & & USAID & \\
\hline 30 & Chk & 2010 & & & SFB & USAID & \\
\hline 31 & $\mathrm{Chr}$ & 2010 & & & SFB & USAID & \\
\hline
\end{tabular}

Source and notes: this table was compiled by the authors from the data file and information obtained at the Kampong Thom provincial office of the Forestry Administration. CF names have been given pseudonyms to prevent our article from giving direct disbenefits to local villagers. Each abbreviation means the following: MB (the Mlup Baitong); AFD (the Action for Development); SFB (the Supporting Forests and Biodiversity Project); EU (the European Union); USAID (the United States Agency for International Development); OGB (the Oxfam Great Britain) and CFMP (Community Forestry Management Plan). 
In addition to clarifying the time period required to establish the rigid and complex processes involved in the Cambodian CF system, another important aspect of this study was to determine which organizations would support such a costly and time-consuming procedure. Organizing and funding the various processes required were far beyond the means of most communities. In the district, two local NGOs, the Mlup Baitong (MB) and the Action for Development (AFD), and an international program, the Supporting Forests and Biodiversity Project (SFB), supported the local communities in undertaking the complex procedures involved. The European Union (EU) and the United States Agency for International Development (USAID) provided funding for the cost-consuming processes. USAID even promised funding for many places where the administration had not yet formally approved CF sites. In addition, the Center for People and Forests (RECOFTC) supported communications among the Forestry Administration, local NGOs, international NGOs and donor organizations to facilitate the realization of the Cambodian CF system, by placing staff in the provincial and central Forestry Administration offices.

\section{The Current Situation Regarding the Use of Cambodian Uplands and Concerns for Community Forestry Development: A Case Study of Sandan District, Kampong Thom Province}

Although logging concessions and subsequently Economic Land Concessions (ELCs) have extensively covered the Cambodian upland areas since the mid-1990s, a separate type of land use rapidly expanded over such areas after the early 2000s; i.e., commercial crop cultivation by small-scale farmers and comparatively large-scale farmers without ELCs. The Sandan District is typical of this trend, with extensive cultivation by small-scale farmers [51]. The district is one of the fastest growing centers of small-scale farming, especially for cassava production, in Cambodia today [52,53].

In the mid-1990s when the security situation stabilized, the government granted logging concessions to some companies. The companies subsequently developed roads to transport timber. After the cancellation or postponement of logging operations in the early 2000s, many households and individuals voluntarily immigrated using the roads, which resulted in a considerable increase in the population of the district, particularly the upper areas. Between 1998 and 2008, when official population censuses were conducted nationwide, while the population growth of Kampong Thom Province was $10.9 \%$, but there was a $28.8 \%$ increase in Sandan District (from 38,574 up to 49,689) [54,55]. Furthermore, in the three upland communes where two-thirds of CF sites in the district are currently located, the population growth was $112.6 \%$ (from 6997 up to 14,880) [54,55]. Figure 2 shows the remarkable increase in commercial crop cultivation in the area of these upland communes. The figure shows the cultivated area of the three major crops in Sandan (SD) District (i.e., wet rice, upland rice and cassava) during 2006-2012. The full and dotted lines show the changes in each crop in the whole district and the three upland communes, respectively. It can be seen that recently, a large expansion of cassava cultivation has occurred within, and around, the upland communes.

The important point in the context of this study is that these changes have occurred in upland areas in similar locations to most of the CF sites, in which the complex and time-consuming processes described earlier have been ongoing. Because of the locational and temporal synchronicity between commercial crop cultivation and CF site development, a competition stemming from the different needs has emerged as a potential concern, although both land use requirements originate from the same local farmers. It would be undesirable if the demand-and-supply balance for farmland becomes urgent due to 
continued population increase and agricultural land expansion, because cultivation pressures would become more intense within CF sites, and finally, some sites would have to be made available for commercial crop production.

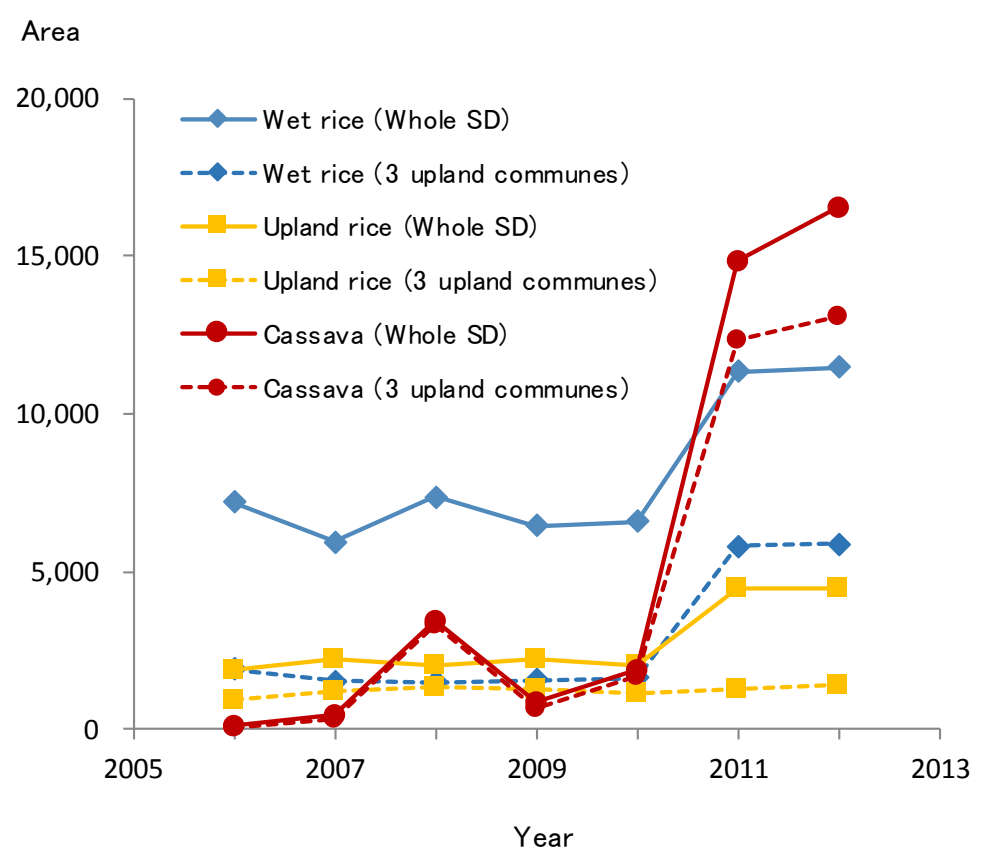

Figure 2. Changes in the cultivated area of three major crops in the study site (2006-2012). Source and note: this figure was developed by the authors from the commune data file obtained at the Ministry of Planning, Phnom Penh, Cambodia.

Figure 3 shows the recent influence of farmland expansion on CF sites, particularly for commercial crops, in upland areas within Sandan District. The yellow polygons with full lines indicate CF sites at the stage of the $\mathrm{CF}$ agreement being contracted between the community and the Forestry Administration. The yellow polygons with longer dotted lines show the CF sites approved by the Forestry Administration without a contract, while the yellow polygons with shorter dotted lines indicate nominated CF sites without both approval and a contract with the Forestry Administration. The background satellite imagery is the Normalized Difference Vegetation Index (NDVI) generated from Landsat imagery taken on 12 January 2009 and 14 January 2014. In Cambodia, January is the middle of the dry season. These two images show the dramatic deforestation in the upland areas during the five-year period due to farmland expansion, mainly for commercial crops. The darker areas indicate natural evergreen forest, arboricultural crop plantation (mainly rubber) and fruit or cashew nuts orchards. The brighter areas are harvested paddy fields, water bodies, such as rivers or swamps, or bare land before planting or after harvesting of crops. The grey-colored areas are deciduous forests, upland crop fields typically for cassava cultivation or grasslands. 

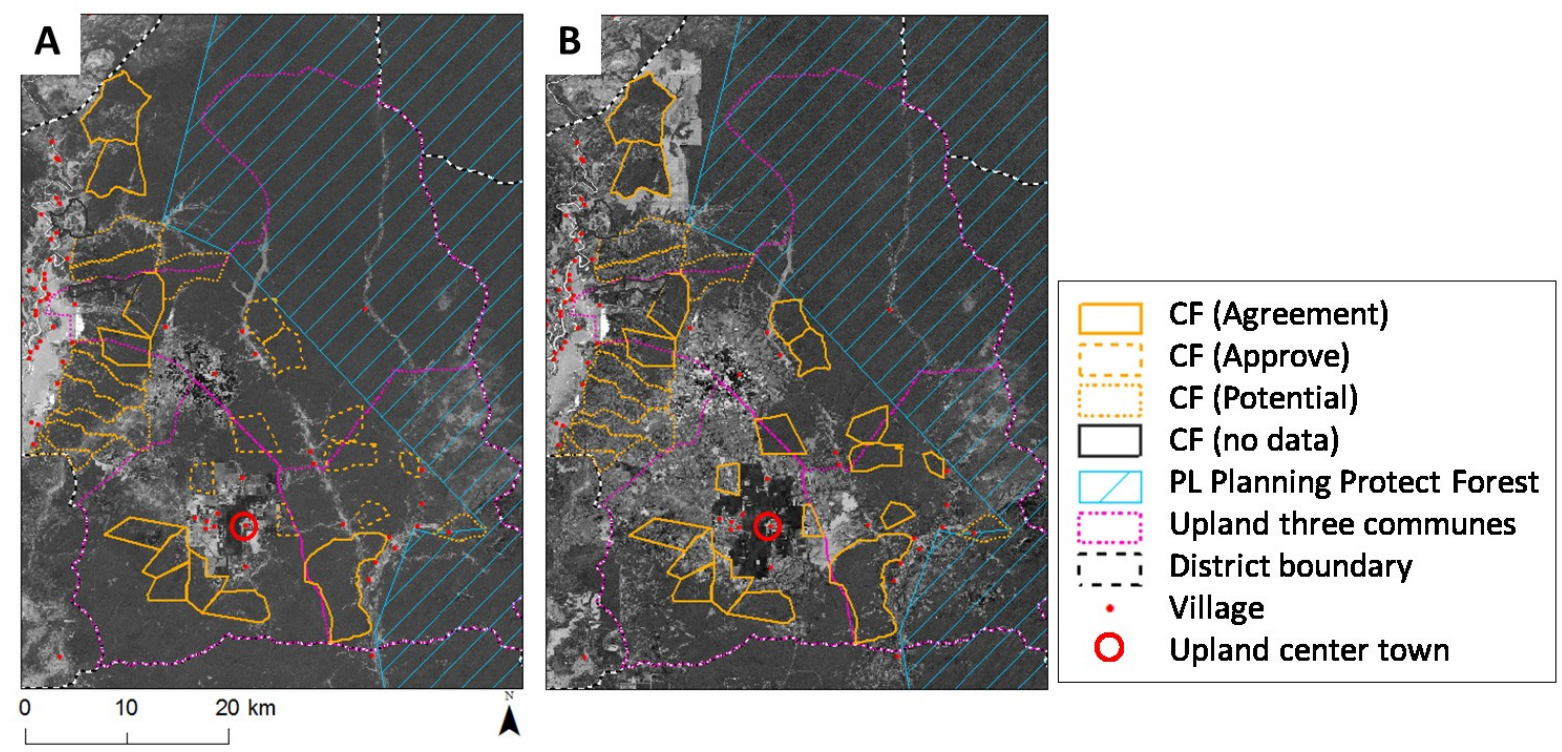

Figure 3. Recent changes in land cover and community forestry (CF) site status in Sandan District, Kampong Thom Province. Source: NDVI of (A) Landsat 5 TM taken on 14 January 2009 and (B) Landsat 7 taken on 11 January 2014. CF statuses for (A, B) were available from the Kampong Thom provincial office of the Forestry Administration and are based on the periods of June 2010 and September 2014, respectively.

On the basis of this figure and our field surveys during 2013-2014, we can summarize the recent situation regarding the prevailing upland use and CF site within the district as follows. Forest vegetation has been preserved in many CF sites without change, but deforestation and the expansion of arable land has occurred in some CF sites. Many preserved CF sites are located in the eastern and northern area around the upland central town of Sandan District (a concentrated area of upland communes shown in Figure 3), particularly in the buffer-like area between agricultural land and natural forest near a planned protected forest zone. Many deforested and cultivated CF sites are located in the southwestern and northwestern areas around the upland central town, which is an area with broader arable land expansion than the eastern and northern area.

Figures 4 and 5 show CF sites that are typical of the two situations discussed. Within each red circle is a zone with a radius of ten $\mathrm{km}$ from the center points of two adjacent $\mathrm{CF}$ sites. Both figures suggest that temporal differences have occurred, with the multidirectional movement of agricultural cultivation around each CF site. Figure 5B shows the situation when agricultural cultivation has moved into the area, although it includes some deciduous forest. Figures $4 \mathrm{~B}$ and $5 \mathrm{~A}$ show the situation when agricultural cultivation arrives in each area. In the two CF sites in Figure 5, CF agreements were signed between the Forestry Administration and CF management committees in November 2009. From Figures 2 and 5A, it can be seen that forest was present within the CF sites at the time when the CF agreements were signed. However, five years later, cassava production by small-scale farmers and some rubber plantations were located within both CF sites, as indicated by Figure 5B. Our field survey confirmed this in January 2014. 

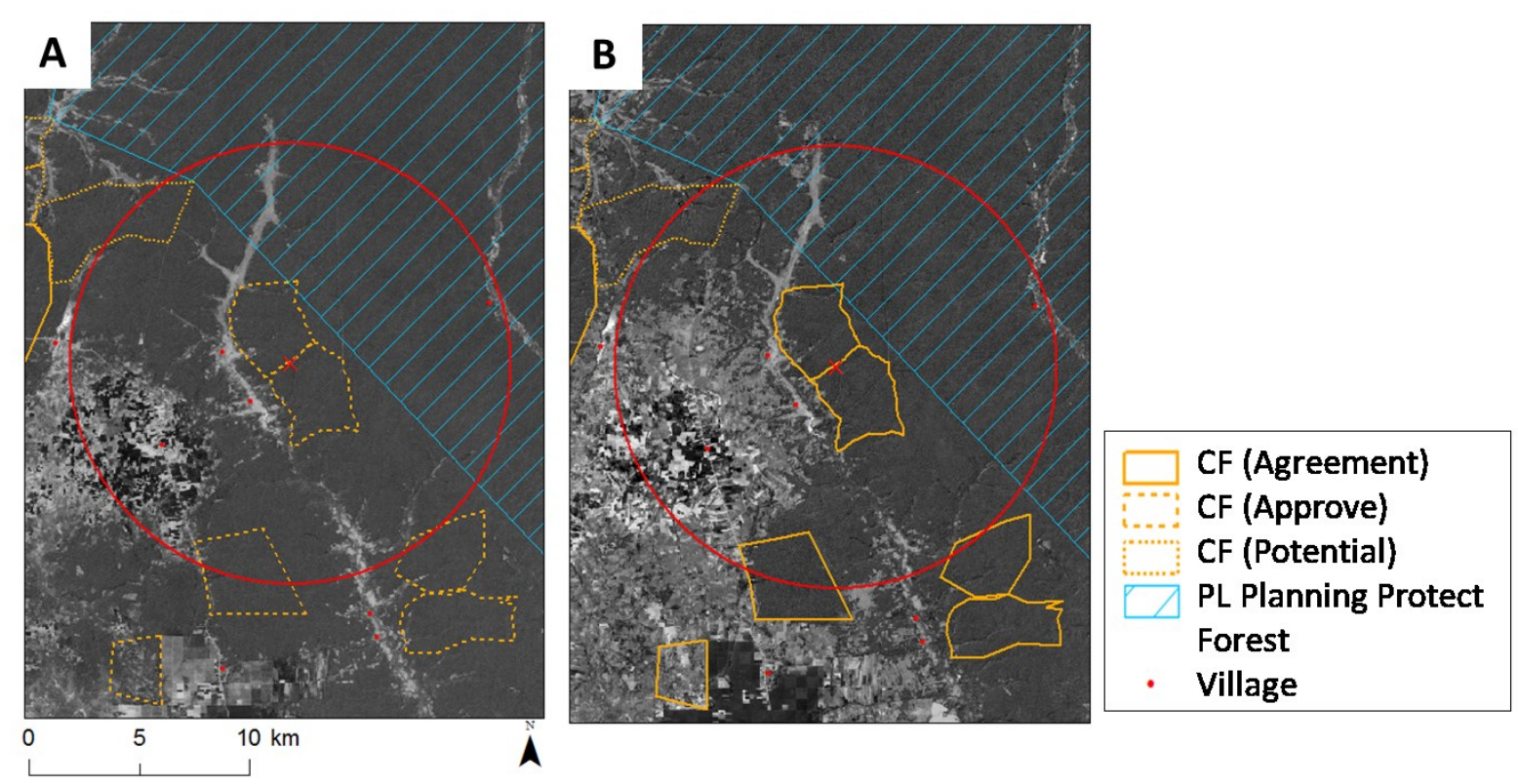

Figure 4. Recent changes in land cover and community forestry (CF) site status in an area with little deforestation within CF sites. Source: NDVI of (A) Landsat 5 TM taken on 14 January 2009 and (B) Landsat 7 taken on 11 January 2014. CF statuses for (A, B) were available from the Kampong Thom provincial office of the Forestry Administration and are based on the periods of June 2010 and September 2014, respectively.
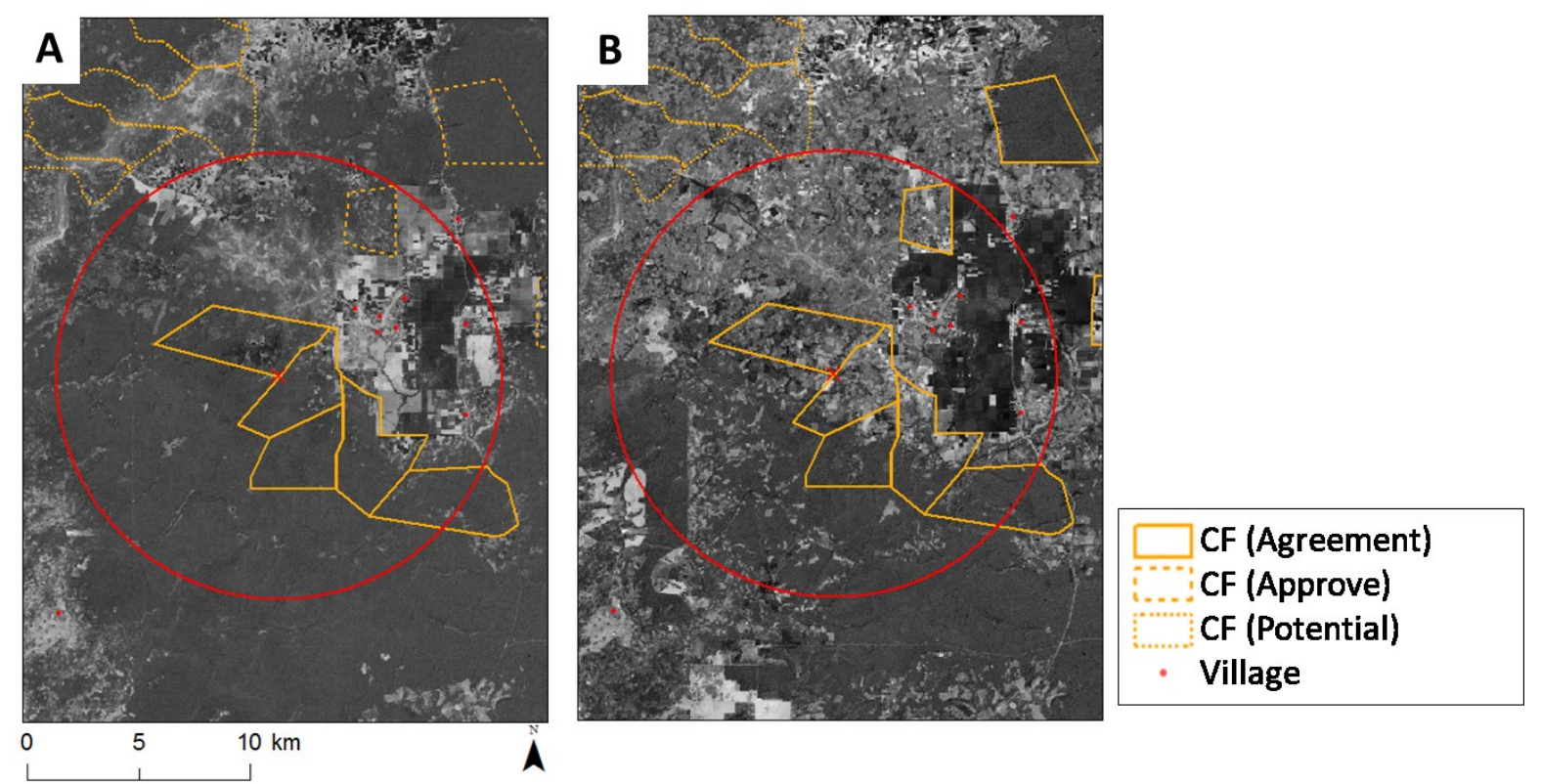

Figure 5. Recent changes in land cover and community forestry (CF) site status in a heavily-deforested area within and around CF sites. Source: NDVI of (A) Landsat 5 TM taken on 14 January 2009 and (B) Landsat 7 taken on 11 January 2014. CF statuses for (A, B) were available from the Kampong Thom provincial office of the Forestry Administration are based on the periods of June 2010 and September 2014, respectively.

This suggests that the signed agreements do not necessarily secure the CF sites against the development of arable land expansion around the regions, and such situations are likely to arise in other local CF sites 
according to the local population and land use dynamics, although forest vegetation currently exists within the CF site. Furthermore, commercial timber harvesting (e.g., as the CF sites in Figure 4 may experience approximately a decade after approval of the CF management plan draft from the Forestry Administration) could be a catalyst to incentivize agricultural land cultivation within the CF sites.

\section{Discussion}

As indicated by the latest statistics [50], more community forestry (CF) sites in Cambodia are currently located in upland areas than in lowland areas. In many parts of these Cambodian upland areas, collective forest management, such as $\mathrm{CF}$, is likely to be a relatively new scheme, as was the case in the example of Sandan District, Kampong Thom Province, in this study. Moreover, at the same time, as these new forest management schemes have been introduced and carried forward, some unprecedented changes have occurred in the upland areas, e.g., a rapid increase in population and a large expansion of commercial crop cultivation. In the final part of this article, we consider the impending problems relevant to the current Cambodian CF system and the means by which those problems might be practically resolved, with the assumption that new experimental trials under the rigid and heavily-regulated existing system are likely to produce many inadequate CF sites in the future, given the expansion of agricultural land and the movement of local residents into upland areas. To consider these practical issues here, we attempted to determine what stakeholders needed and how this has led to the introduction and operation of such a rigid CF system, as clarified in the third chapter.

In addition to the nature of bureaucracy, which some have indicated using cases in other developing counties, the important factors that enabled the rigid and heavily-regulated CF system to be introduced and upheld in Cambodia were associated with the responses and roles of international societies, national and international non-governmental organizations (NGOs) and other organizations. These external bodies have directly or indirectly been engaged in the development of the current Cambodian CF system. Without the engagement of such external bodies, the CF system could not have operated. What structures and underlying causes have encouraged these external bodies to give their approval to the CF system and subsequently to deliver various levels of support, particularly funding? We pointed to the structure of the interplay that the Cambodian administration and international societies bred. In addition, we acknowledged the trade-off situation that existed in the mid-2000s between CF and Economic Land Concession (ELC) sites when logging concessions were cancelled or postponed. The situation heightened the need to rapidly introduce the official CF guideline and to secure CF sites for local communities. Then, once scheduled and enacted, the CF system became a vehicle for international assistance aid and an important tool for driving the National Forest Program (NFP). Through such a process of development, the Cambodian CF system has received more funding support from large donor organizations (e.g., the European Union and United States Agency for International Development) to implement the time- and cost-consuming process than before the rigid CF system was introduced.

As repeatedly mentioned, the current Cambodian CF system was established through the proclamation and enforcement of the 2006 CF Guideline. Although more than eight years have subsequently passed, no major conflict between communities and the Forestry Administration over the CF sites has been reported. Has the rigid and heavily-regulated CF system operated successfully with the changing land uses in the Cambodian uplands? We believe that the likely conflicts have not yet emerged due to the 
backlogs in implementation of CF agreement cancellations by the administration or in the CF management plans, which are still being prepared and are therefore not yet fully operational. For example, we estimate that the two CF cases shown in Figures 4 and 5 are typical examples in which confrontations have been evaded due to the above two types of backlog, respectively. Within the CF site shown in Figure 5, a great deal of arable land is being used for commercial crop cultivation, despite the agreement between the CF management committee and the Forestry Administration to utilize it as a CF site. At the CF site shown in Figure 4, it is likely that the impending extensive commercial timber harvest will encourage some local farmers to cultivate land within the area.

In both of these situations, confrontations are likely once the administration begins to accuse some local farmers of undertaking illegal cultivation or does to deprive communities of CF management rights in accordance with the regulations after sites have been inspected and evaluated. Penalties for illegal farming and punishments for communities that violate the $\mathrm{CF}$ contracts are essential to maintain the $\mathrm{CF}$ sites and systems. If no countermeasures are taken, illegal cultivators will be encouraged, and irresponsible communities may directly or indirectly promote arable land expansion for commercial crop cultivation within the areas designated for CF. However, the actual implementation of such control processes will inevitably create conflicts between the administration and local residents.

The successful implementation of the experimental operation, i.e., the attempt at collective CF management based on the rigid and heavily-regulated CF system, would be a great achievement for sustainable forest management in developing countries such as Cambodia. Nevertheless, the high regulatory burden and the environmental conditions surrounding each CF site are likely to produce many unfavorable experimental results. Two possible practices to address the likely situation could be considered: a complete about-face to adopt a new policy, such as "simpler management plans" and "minimum standards", or complementary and remedial support for the current CF system based on a selective and intensive policy strategy. Here, we consider the practical desirability of the latter option. There are two reasons for considering this option. First, little time is available for experiments based on the new methods because of the extensive commercial crop cultivation that is expanding over the upland area. Second, international societies, as well as the Cambodian administration, need to take responsibility for the continued costs of the experimental sites and methods that originated from their reception of the current CF system and various levels of subsequent support. Assistance aid organizations need to take particular note of having continued to support the current rigid CF system despite counterproposals, and do to fulfil their obligations to each taxpayer and to the local communities by providing possible practical options under the current CF system.

In addition to the effective implementation of embedded Step 9 (i.e., enterprise and livelihood development for community), a pressing, worthwhile and practical challenge for the current Cambodian CF system involves developing a transparent and strong network of CF management committees and investing substantial resources toward it. There are five reasons for this. First, particularly in Nepal, it is claimed that actively networked organizations can contribute more to robust CF management (see [56,57]). Second, no proper network of CF management committees and no motivation for such networking currently exists in Cambodia, with most existing support being focused on the widespread establishment of CF sites and the preparation of CF management plans, despite the existence of efforts to conduct another type of networking, namely networking among local and international non-governmental organizations (NGOs), the limited number of local CF management committee members, the administration 
and overseas CF management committee groups (see [58-60]). Third, the National Forest Program, which represented the consensus between international stakeholders and the government concerning the Cambodian forest management strategy, installed the measure, although only quite briefly. The concept of "evolving into a self-managed federation" was advocated [16]. Fourth, the measure is reasonable for the Cambodian government and donor organizations in terms of the budget, because it can be executed by the rearrangement of allocated domains, such as by delaying the implementation of some difficult planned CF sites and then allocating the resources prepared for them. Fifth, the sound development of a CF management committee network is likely to be a useful way to more desirably and completely satisfy the three basic values that international societies consider necessary for CF management: poverty alleviation, empowerment of forest users and forest conservation [13], with a particular emphasis on the latter two values.

There is a high possibility that individual CF management committees would not discourage local farmers from undertaking commercial crop cultivation within CF sites located in areas where the population has increased. If the government then adopts a shotgun approach for inconvenient matters within many problematic CF sites, it could hinder the appropriate development of CF by reversing the cart and the horse. However, allowing the situation to continue without any mechanism for control might result in further cultivation. A network of CF management committees, perhaps in the form of a federation, could deal with illegal cultivators and irresponsible communities instead of, or in tandem with, the administration's efforts to do so. Thus, the paradoxical situation concerning CF management presented in the Introduction would be prevented (as Fisher feared [8]); i.e., strengthened central bureaucratic power will lead to the disempowerment of forest users in return for forest conservation, although a phase may arise when the empowered CF management committee network will come into conflict with the administration over some CF policies.

\section{Conclusions}

This case study from Cambodia found that governments and some international organizations have played key roles in the introduction and maintenance of rigid, complex, expensive community forestry (CF) systems in developing countries, despite critiques of and counterproposals to such systems. Although the main problems stemming from CF systems have yet to be identified, at least in countries such as Cambodia, conflicts are likely to arise when administrations prosecute local farmers for existing illegal cultivation or deprive communities of CF management rights because of the lack of adequate management. If the governments and international organizations responsible for such situations address improving CF management systems, we believe that practical options should be adopted that attempt to balance the basic ideas that international societies value for CF management with the unfavorable realities of $\mathrm{CF}$ management that rural societies in developing countries face under the current global economy. When considering such a balance, supporting the development of networks for CF committees is a better policy option than the adoption of entirely new alternative systems.

\section{Acknowledgments}

The authors wish to thank many villagers and village leaders in the study site, Sopet Thong, Kea Ly, James Bampton, Sophana Om, staffs of Mlup Baitong, Atsuko Hayama, Borin Too and Bora Tith for 
providing information and supporting data collections regarding community forestry in Cambodia and other countries. The authors also thank Hao Gong for his support of GIS data preparation. This study was conducted as part of a project on "Estimation and simulation of carbon stock change of tropical forest in Asia (2011-2014)," supported by the Ministry of Agriculture, Forestry and Fisheries, Japan.

\section{Author Contributions}

Takayuki Kurashima carried out fieldwork, collected and analyzed data, and wrote the paper. Toshiya Matsuura conducted data analysis and description regarding the spatial information such as satellite imagery, distributions of villages and CF sites, as well as having contributed to conceptual development for the manuscript. Asako Miyamoto, Makoto Sano and Sophal Chann coordinated the research and research project in Japan and Cambodia.

\section{Conflicts of Interest}

The authors declare no conflict of interest.

\section{Abbreviation List}

$\begin{array}{ll}\text { CF } & \text { Community forestry } \\ \text { CFA } & \text { Community forestry agreement } \\ \text { CFMC } & \text { Community forestry management committee } \\ \text { CFMP } & \text { Community forestry management plan } \\ \text { ELC } & \text { Economic Land Concession } \\ \text { NDVI } & \text { Normalized Difference Vegetation Index } \\ \text { NFP } & \text { National Forest Program } \\ \text { NGO } & \text { Non-governmental organization } \\ \text { RECOFTC } & \text { Center for People and Forests (the former name was } \\ & \text { Regional Community Forestry Training Center for Asia } \\ & \text { and the Pacific) } \\ \text { SD } & \text { Sandan (district) }\end{array}$

\section{References}

1. Forestry Policy and Institutions Service. Simpler Forest Management Plans for Participatory Forestry; FAO: Roma, Italy, 2004; p. 68.

2. Poffenberger, M.; Soriaga, R.; Walpole, P. Communities and Forest Stewardship: Regional Transition in Southeast Asia; Asia Forest Network: Bohol, Philippines, 2006; p. 150.

3. Pulhin, J.M.; Larson, A.M.; Pacheco, P. Regulations as barriers to community benefits in tenure reform. In Forest for People: Community Rights and Forest Tenure Reform; Larson, A., Barry, D., Dahal, G., Colfer, C., Eds.; Earthscan: London, UK, 2010; pp. 139-159.

4. Forestry Department. Reforming Forest Tenure: Issue, Principles and Process; FAO: Roma, Italy, 2011; p. 92. 
5. Cronklleton, P.; Pulhin, J.M.; Saigal, S. Co-management in community forestry: How the partial devolution of management rights creates challenges for forest communities. Conserv. Soc. 2012, 10, 91-102.

6. Larson, A.M.; Pulhin, J.M. Enhancing forest tenure reforms through more responsive regulations. Conserv. Soc. 2012, 10, 103-113.

7. RECOFTC (The Center for People and Forests). Current Status of Social Forestry in Climate Change Mitigation and Adaptation in the ASEAN Region: Situational Analysis 2013; RECOFTC: Bangkok, Thailand, 2014; p. 100.

8. Fisher, R.J. Lessons Learned from Community Forestry in Asia and their Relevance for REDD+; USAID-Supported Forest Carbon, Markets and Communities Program: Washington, DC, USA, 2014; p. 35.

9. Larson, A.M.; Ribot, J.C. The poverty of forestry policy: Double standards on an even playing field. Sustain. Sci. 2007, 2, 189-204.

10. Porter-Bolland, L.; Ellis, E.A.; Guariguata, M.R.; Ruiz-Mallén, I.; Negrete-Yankelevich, S.; Reyes-García, V. Community managed forests and forest protected areas: An assessment of their conservation effectiveness across the tropics. For. Ecol. Manag. 2012, 268, 6-17.

11. Bowler, D.E.; Buyung-Ali, L.M.; Healey, J.R.; Jones, J.P.; Knight, T.M.; Pullin, A.S. Does community forest management provide global environmental benefits and improve local welfare? Front. Ecol. Environ. 2012, 10, 29-36.

12. Casse, T.; Milhøj, A. While waiting for the answer: A critical review of meta-studies of tropical forest management. J. Environ. Manag. 2013, 131, 334-342.

13. Maryudi, A.; Devkota, R.R.; Schusser, C.; Yufanyi, C.; Salla, M.; Aurenhammer, H.; Rotchanaphatharawit, R.; Krott, M. Back to basics: Considerations in evaluating the outcomes of community forestry. For. Policy Econ. 2012, 14, 1-5.

14. Ojha, H. Aid Dilemma: Has Foreign Aid Contributed in Community Forestry in Nepal, AAMN Research and Policy Brief 06; Alliance for AID Monitor Nepal: Kathmandu, Nepal, 2011; p. 13.

15. Bampton, J.; Heng, D.; Long, R. Partnerships for Community Forestry Development in Cambodia. Available online: http:/www.forestrynepal.org/images/02-\%20Presented\%20Papers\%20and\%20 Powerpoints/Theme\%201/Paper/09-\%20Bampton\%20et\%20al_Cambodia.pdf (accessed on 15 March 2013).

16. Kingdom of Cambodia. National Forest Programme 2010-2029, Unofficial Translation; Ministry of Agriculture, Forestry and Fisheries: Phnom Penh, Cambodia, 2010; p. 144.

17. RECOFTC (The Center for People and Forests). Community Forestry Adaptation Roadmap to 2020 for Cambodia; RECOFTC: Bangkok, Thailand, 2014; p. 39.

18. Blomley, T.; Prom, T.; Mam, K.; Eam, D.; Dubois, M. Review of Community Forestry and Community Fisheries in Cambodia: Report Prepared for the National Resource Management and Livelihood Programme; USAID: Washington, DC, USA, 2010; p. 52.

19. Kingdom of Cambodia. Law on Forestry, Unofficial Translation; Open Development Cambodia: Phnom Penh, Cambodia, 2002; p. 36.

20. Hobley, M. Formal legal and informal framework for forestry in cambodia. In The Forest Sector in Cambodia, Part 2: Current Context; Working Group on Natural Resource Management, Ed.; Royal Government of Cambodia: Phnom Penh, Cambodia, 2004; pp. 1-65. 
21. Kingdom of Cambodia. Sub-Decree on Community Forestry Management, Unofficial Translation; Open Development Cambodia: Phnom Penh, Cambodia, 2003; p. 12.

22. Kingdom of Cambodia. Guideline on Community Forestry and its Relevant Policies, Unofficial Translation; Forestry Department: Phnom Penh, Cambodia, 2006.

23. Poffenberger, M.; Long, R. Implementation of the national community forestry program. In Cambodia's Contested Forest Domain: the Role of Community Forestry in the New Millennium; Poffenberger, M., Ed.; Ateneo De Manila University Press: Manila, Philippines, 2013; pp. 263-273.

24. World Bank. Cambodia Forest Policy Assessment; World Bank: Washington, DC, USA, 1996; p. 60 .

25. Royal Government of Cambodia. Interim Report: Sustainable Forest Management Project Cambodia; Ministry of Agriculture, Forestry and Fisheries: Phnom Penh, Cambodia, 1999.

26. Royal Government of Cambodia. Cambodian Forest Concession Review Report: Sustainable Forest Management Project; Ministry of Agriculture, Forestry and Fisheries: Phnom Penh, Cambodia, 2000.

27. Provincial Department of Forestry. Community Forestry in Cambodia: Guidelines for Development; Provincial Department of Forestry: Siem Reap, Cambodia, 2004; p. 62.

28. Royal Government of Cambodia. Community Forestry Guidelines: Sustainable Forest Management Project; Ministry of Agriculture, Forestry and Fisheries: Phnom Penh, Cambodia, 2000; p. 45.

29. Associates in Rural Development. Forest Policy Reform Project: Forest Policy Transition Paper for Cambodia Final Draft; ARD: Burlington, VT, USA, 1998.

30. Poffenberger, M. Cambodia's contested forest domain: A historical perspective. In Cambodia's Contested Forest Domain: The Role of Community Forestry in the New Millennium; Poffenberger, M., Ed.; Ateneo De Manila University Press: Manila, Philippines, 2013; pp. 3-33.

31. World Bank. Cambodia-Forest Concession Management and Control Pilot Project: Request for Inspection-Inspection Panel Report and Recommendation; World Bank: Washington, DC, USA, 2005.

32. Technical Working Group on Forestry Reform. TWG-FR Meeting. Available online: http://wgfr. org/meetings/twg-fr-meeting.html (accessed on 29 July 2014).

33. Braeutigam, D. Community Based Forest Management in Cambodia and Laos: Frame Conditions, Selected Examples and Implications; MRC-GTZ Cooperation Programme: Phnom Penh, Cambodia, 2003; p. 95.

34. Oberndorf, R.B. Legal Analysis of Forest and Land Laws in Cambodia; Community Forestry International: South Lake Tahoe, CA, USA, 2006; p. 38.

35. RECOFTC (The Center for People and Forests). Challenges for Cambodia. Available online: http://www.recoftc.org/site/Challenges-for-Cambodia (accessed on 10 April 2014).

36. RECOFTC (The Center for People and Forests). Community Forestry in Cambodia. Available online: http://www.recoftc.org/site/Community-Forestry-in-Cambodia (accessed on 29 July 2014).

37. RECOFTC (The Center for People and Forests). Annual Report: Summary Highlights October 2007-September 2008; RECOFTC: Bangkok, Thailand, 2008; p. 34.

38. RECOFTC (The Center for People and Forests). A Brighter Future for People and Forests: Annual Report October 2010-September 2011; RECOFTC: Bangkok, Thailand, 2011; p. 10. 
39. COHCHR (United Nations Cambodia Office of the High Commissioner for Human Rights). Land Concessions for Economic Purposes in Cambodia: A Human Rights Perspective; COHCHR: Phnom Penh, Cambodia, 2004; p. 86.

40. COHCHR (United Nations Cambodia Office of the High Commissioner for Human Rights). Economic Land Concessions in Cambodia: A Human Rights Perspective; COHCHR: Phnom Penh, Cambodia, 2007; p. 35.

41. Saing, C.H.; Hem, S.; Ouch, C.; Phann, D.; Pon, D. Foreign Investment in Agriculture in Cambodia, CDRI Working Paper Series No. 60; Cambodia Development Research Institute (CDRI): Phnom Penh, Cambodia, 2012; p. 62.

42. World Bank. World Bank to Support Community Forestry and Participation in Cambodia. Available online: http://web.worldbank.org/WBSITE/EXTERNAL/COUNTRIES/AFRICAEXT/EXTAFR SUMESSD/EXTFORINAFR/0,,contentMDK:21048905 menuPK:2493506 pagePK:64020865 p iPK:149114 theSitePK:2493451,00.html (accessed on 29 July 2014).

43. Independent Forest Sector Review. Available online: http://twgfr.org/download/Study\%20Reports (2)/1-Independent\%20Forest\%20Sector\%20Review-April\%202004.pdf (accessed on 1 July 2013).

44. Sothath, N.; Sophal, C. Economic Land Concessions and Local Communities; The NGO Forum on Cambodia's Forestry Rights Project of Land and Livelihoods Programme: Phnom Penh, Cambodia, 2012; p. 63.

45. ADHOC (Cambodian Human Rights and Development Association). A Turning Point? Land, Housing and Natural Resources Rights in Cambodia in 2012; ADHOC: Phnom Penh, Cambodia, 2013; p. 47.

46. Müller, F. Commune-Based Land Allocation for Poverty Reduction in Cambodia: Achievements and Lessons Learned from the Project: Land Allocation for Social and Economic Development (LASED); World Bank: Washington, DC, USA, 2012; p. 23.

47. Matsuura, T.; Miyamoto, A.; Kurashima, T.; Sano, M.; Chann, S.; Pak, C.; Leng, C. Spatial characteristics of recent deforestation and the effects of zoning in the upper Chinit river basin, central Cambodia. In Forest Watershed Environment Research in Cambodia, Proceedings of 8th International Workshop on, Phnom Penh, Cambodia, 14 November 2012; Shimizu, A., Chann, S., Sawada, H., Ohnuki, Y., Tamai, K., Eds.; Forestry and Forest Products Research Institute, Japan and Forestry Administration Cambodia: Tsukuba, Japan, 2012; pp. 41-44.

48. Oberndorf, R.B. Overview of the policy and legal framework for CBRNM. In The Development of Community Based Natural Resource Management (CBNRM) in Cambodia; Rotha, K., Carson, T., Riebe, K., Cox, S., Kaschke, E., Eds.; CBNRM Learning Initiative: Phnom Penh, Cambodia, 2005; pp. 59-72.

49. UN data, A World Information. Available online: http://data.un.org/CountryProfile.aspx?crName =Cambodia (accessed on 2 March 2015).

50. Kingdom of Cambodia. Community Forestry Statistic in Cambodia 2013; Forestry Administration: Phnom Penh, Cambodia, 2013; p. 30.

51. Kurashima, T.; Matsuura, T.; Miyamoto, A.; Sano, M.; Tith, B.; Chann, S. Changes in income structure in frontier villages and implications for REDD+ benefit sharing. Forests 2014, 5, 2865-2881. 
52. National Institute of Statistics. Census of Agriculture in Cambodia 2013: Preliminary Report; Ministry of Planning: Phnom Penh, Cambodia, 2014; p. 33.

53. Hing, V.; Thun, V. Agricultural Trade in the Greater Mekong Sub-Region: The Case of Cassava and Rubber in Cambodia; CDRI: Phnom Penh, Cambodia, 2009; p. 59.

54. Kingdom of Cambodia. CD-Rom with Village Level Data, CD-Rom No. 2, General Population Census of Cambodia 1998; National Institute of Statistics: Phnom Penh, Cambodia, 2000.

55. Kingdom of Cambodia. General Population Census of Cambodia 2008; National Institute of Statistics: Phnom Penh, Cambodia, 2009.

56. Ojha, H.; Persha, L.; Chhatre, A. Community Forestry in Nepal: A Policy Innovation for Local Livelihoods; International Food Policy Research Institute: Washington, DC, USA, 2009; p. 35.

57. Paudel, N.S.; Monterroso, I.; Cronkleton, P. Community networks, collective action and forest management benefits. In Forest for People: Community Rights and Forest Tenure Reform; Larson, A., Barry, D., Dahal, G., Colfer, C., Eds.; Earthscan: London, UK, 2010; pp. 116-136.

58. Thayuth, C.; Sopheary, O. Community forestry and community protected area network. In the Development of Community Based Natural Resource Management (CBNRM) in Cambodia; Rotha, K., Carson, T., Riebe, K., Cox, S., Kaschke, E., Eds.; CBNRM Learning Initiative: Phnom Penh, Cambodia, 2005; pp. 107-118.

59. Bradley, A. Natural Resources Management Networking in Cambodia: Status, Lessons Learned, and Future Possibilities; Community Forestry International: South Lake Tahoe, CA, USA, 2006; p. 61.

60. RECOFTC (The Center for People and Forests). Taking Action for Community Forestry in Cambodia. Available online: http://www.recoftc.org/site/Taking-action-for-community-forestry -in-Cambodia-.php (accessed on 11 August 2014).

(C) 2015 by the authors; licensee MDPI, Basel, Switzerland. This article is an open access article distributed under the terms and conditions of the Creative Commons Attribution license (http://creativecommons.org/licenses/by/4.0/). 